\title{
PECULIARITIES IN INVESTIGATING THE CRIME SCENE IN CASE OF EXPLOSIONS
}

\author{
N. E. Buzatu
}

\section{Nicoleta-Elena Buzatu}

Faculty of Juridical and Administrative Sciences

"Dimitrie Cantemir" Christian University, Bucharest, Romania

*Correspondence: Nicoleta-Elena Buzatu, "Dimitrie Cantemir" Christian University, 176

Splaiul Unirii, 4 District, Bucharest, Romania

E-mail: nicoleta_buzatu@yahoo.com

\section{Abstract}

Explosions are a real threat for the life, the bodily integrity and the health of the people, as well as for the public and private property. The investigation of the crime scene is a high risk activity because of the complexity of the large scale damages, the large area involved due to the blast of the explosion and to the partial character of the imprints. According to the Romanian penal legislation, explosions are not considered to be independent infringements of the law; yet they are defined as means of producing other infringements as, for instance, the infringement of destruction in an aggravating stage, as stipulated by the Penal Code.

Key words: explosions, investigation of the crime scene, imprints, evidence/proofs, investigation

\section{Introduction}

The explosion is a very quick and violent physical or chemical reaction accompanied by mechanic, sonorous, thermic, bright effects, etc. as the result of the decomposition of certain explosive elements a destruction device may contain ${ }^{1}$. A large quantity of gas with destructive effects over the persons and objects in the proximity of the detonation will be relieved.

At the same time, an explosion is a very complex technical phenomenon that can be done in a very large number of ways and has very unexpected consequences. Its characteristics raise problems in the investigations meant to demonstrate the causes and the culprits responsible for generating the explosion².

From the chemical point of view, an explosion is a series of oxidizing reaction phenomenon.

The most obvious difference between fire and explosion lies in the fact that, although the explosion is thought to be another type of burning, it acts with such a high speed that it can practically be considered instantaneous ${ }^{3}$.

Explosions are followed by fire because, the moment an explosion is released, a very high temperature is given out which, consequently, sets fire to all the inflammable materials

\footnotetext{
${ }^{1}$ DEX - Explanatory Dictionary of the Romanian Language, Univers Enciclopedic Printing House, Bucharest, 1998, pp. 539.

${ }^{2}$ Matei, A.; Feraru D.L. - Peculiarities in the Forensic Investigation of Terrorism Attacks Using Explosives, in The Contribution of Forensic Sciences in Investigating Terrorist Acts and of Seriously Other Dramatic Events, Bucharest, 2007, pp. 146.

${ }^{3}$ Stoica, V. - Investigating Special Events (fires, explosions), in Guidebook of the Forensic Prosecutor, vol. II, Helicon Printing House, 1994, pp. 9.
} 
in the area.

This violent generation and release of gas is one of the first criteria of an explosion that can define the other important types of explosions: mechanic, chemical and nuclear ${ }^{4}$.

The explosion can also be generated by a spontaneous combustion/ ignition of certain substances, in case it accumulates the necessary agents.

A mechanical explosion is accompanied by very high temperatures, by a very quick release of gas and vapours, as well as by a very loud noise.

A chemical explosion is generated by a very quick conversion of a solid or liquid explosive into gas and, it is accompanied by very high temperatures and by an astounding noise.

The nuclear explosion can be generated by fission or fusion. The consequence is a huge quantity of energy, heat and gas, followed by fire. By the way the explosion grows after the release, it destroys the imprints because it burns all the inflammable or heavy inflammable materials or, because of the serious damage produced to the fireproof materials.

Aspects regarding the investigation of the crime scene

The lab probative procedure - defined in art 129 by the Romanian Penal Code of Procedure as an investigation of the crime scene - is the first measure to be taken in investigating extremely dangerous deeds. In conformity with the above mentioned article this procedure is applied then when it is necessary to reach conclusions concerning the state of the crime scene, to discover and establish the traces of the infringement, to fix the position and the state of the proofs and to settle the circumstances the deflagration took place.

In as far as an explosion is concerned the crime scene means the place where the explosion took place and the area between the center of the deflagration and the distance up to where the blast acted - both on a vertical and on a horizontal plane.

The experts take into account two distinctive stages in the investigation of the crime scene: the static and the dynamic one. In practice, this distinction is somehow conventional. In reality the two stages are rigorously intermingled, fact which does not appear to be very important if the integrity of the material proofs is preserved ${ }^{5}$.

The static stage is the first contact with the crime scene, when the investigation is reduced to observation only - with no touching anything. Data regarding the general situation will be obtained and used in preventing or avoiding other explosions to happen, in giving the first aid to victims, as well as in obtaining other details about what had happened at the moment of the explosion or, in getting information about the changes which have been noticed and of what nature, in inquiring about the type of activity carried on at the moment of the explosion and in recording all witnesses' and victims' declarations.

The dynamic stage involves the removal and the attentive examination - with maximum precaution - of the objects. This is the most complex stage, as it involves the participation of all the members of the team. All transmitting stations, measuring and control devices will be sealed and the state and the position of the inflammable or under pressure equipments will be checked. The ground of aggression and the crater will be looked for and after, the investigation for the discovery, establishing, prevailing and analyzing the traces, as reported to the place and type of explosion will be seriously examined.

The investigation proper will take place in conformity with the following tactical rules $^{6}$ : the investigation of the crime scene shall be done immediately - but avoiding speed and superficiality -, shall be made systematically and shall be objective and complete. The team

\footnotetext{
${ }^{4}$ Lăpădu $\square \mathrm{i}$, V.; Popa, G. - Forensic Investigation of the Crime Scene, LUCEAFĂRUL Printing House, Bucharest, 2005, p. 133.

${ }^{5}$ Ionescu, L., Forensic Science, Bucharest, Pro Universitaria Printing House, 2007, p. 29.

${ }^{6}$ For more details see: Cârjan, L.; Chiper, M. - Forensic Science. Tradition and Modernism, Curtea Veche Printing House, Bucharest, 2009, p. 280 and next.
} 
shall be led by chief: he has to coordinate all activities and guide them, to strictly respect the procedures, to correctly respect the relationship with the mass-media and, to analyze the results obtained.

Identifying the explosion scene

The explosion scene is marked by various sized craters depending on the amplitude of the explosion and on the quantity of explosive matter used. The constructions and the installations around are deformed or destroyed from the centre to the outside.

The search of the open places generally starts from the center to the periphery, concentrically or spirally, progressively enlarging the investigated area.

If the explosion took place inside a room or building, the deformation of the walls is oriented towards the interior; all traces of burns, smoke, distortions produced by the blast or by fire will be taking into account.

To identify the place where the explosive materials are stored and to find out the persons who are in their possession and use them, special means and methods are resorted to, as well as explosive detecting trained dogs.

After having removed all the devices and the potential dangers generated by the explosion the investigation team can enter the crime scene. Rescuing measures have priority in the looking for and picking up of proofs.

Proofs Drawing

Before removing the proofs from the explosion scene, the area is marked and minutely photographed or mentioned in the official report; scaled drafts and the position of the found marks and traces should be cautiously mentioned.

From the explosion scenes there are raised earth proofs, ceramics samples, plaster, ashes from the floor of the rooms and other burnt objects, textile fibers/ patches, inflammable liquids found in either the area or in the possession of suspects. There are also raised fragments of materials taken from the crater of the explosion (earth, concrete, wood, etc) as well as fragments of dubious materials coming from the improvised explosive device or from the initiation devices, wicks, containers and wrappers, ammunition, hand grenades, shell splinters, etc.

There can be also found rests from the unexploded explosive material, rests of wicks or of plastic explosives.

Proofs-gathering should be sufficient and carefully handled, wrapped in tight sealed glass vessels as to avoid casual impurities altering the tests or making the volatile substances evaporate. Wrapping the tests/ proofs is done in such a way as to prevent the loss of the evaporating substances and their contamination from other external sources, during the transport.

Explosive smell samples can be raised from the explosion scene only with special devices - absorbing materials, syringe or aspirator - and be tested with trained dogs, if the respective samples contain such traces and if they were raised after a period of time since the event.

The unexploded devices or the explosive materials are raised, handled, wrapped and transported by pyrotechnical technicians.

The problems that can be solved by investigating the consequences of an explosion ${ }^{7}$ are the following: the nature of the trace; whether the trace was the consequence of the explosion; the nature and the causes of the explosion; the nature and the type of the explosive material; the type of the detonation device; resemblances between the traces of the explosive substances discovered at the explosion scene and the explosive substances used as a comparative model from a chemical point of view; the technical state of the apparatuses

\footnotetext{
${ }^{7}$ Ionescu, F. - Forensic Science, Universitară Printing House, Bucharest, 2008, p. 208.
} 
recording the pressure and the temperature of the cisterns containing explosive-property substances.

\section{Conclusions}

The investigation of the explosion scene shall be very carefully and minutely done having in view the discovery of all the fragments of the explosive device in order to help the reconstitution.

Beside the already mentioned peculiarities, the evolution and materialization of the results of the investigation take place at the explosion scene in conformity with the general rules. In open places the activity of searching for proofs generally starts from the center of the explosion to the periphery, in concentric or spiral circles. In the case of explosions produced in an "explosive atmosphere" traces of burn and wall smoke will be looked for.

Because of the very specific character of the explosions, the cooperation between the legal organs and the experts who are present at the explosive scene is absolutely necessary; it is only in this way that the circumstances and the causes leading to such events should be established and solved.

\section{Bibliography}

Cârjan, L.; Chiper, M. - Forensic Science. Tradition and Modernism, Curtea Veche Printing House, Bucharest, 2009.

DEX - Explanatory Dictionary of the Romanian Language, Univers Enciclopedic Printing House, Bucharest, 1998.

Ionescu, F. - Forensic Science, Universitară Printing House, Bucharest, 2008.

Ionescu, L., Forensic Science, Bucharest, Pro Universitaria Printing House, 2007.

Lăpădu $\square \mathrm{i}, \mathrm{V}$.; Popa, G. - Forensic Investigation of the Crime Scene, LUCEAFĂRUL Printing House, Bucharest, 2005.

Matei, A.; Feraru D.L. - Peculiarities in the Forensic Investigation of Terrorism Attacks Using Explosives, in The Contribution of Forensic Sciences in Investigating Terrorist Acts and of Seriously Other Dramatic Events, Bucharest, 2007.

Stoica, V. - Investigating Special Events (fires, explosions), in Guidebook of the Forensic Prosecutor, vol. II, Helicon Printing House, 1994. 